\title{
Visual impact assessment of river regulation structures
}

\author{
Rafat Wróżyński ${ }^{1, *}$, Krzysztof Pyszny ${ }^{2}$, and Mariusz Sojka ${ }^{1}$ \\ ${ }^{1}$ Faculty of Environmental Engineering and Spatial Management, Poznań University of Life Sciences, ul. Piątkowska 94, 60-649 Poznań, \\ Poland \\ ${ }^{2}$ EnviMap, ul. Piątkowska 118/31, 60-649 Poznań, Poland
}

\begin{abstract}
The paper presents the quantitative methodology for visual impact assessment of river regulation structures such as non-submerged groins and longitudinal dams. The method integrates LIDAR data, GIS tools, 3D graphic software and $360^{\circ}$ panoramic images. Digital Surface Model (DSM) developed on the basis of LIDAR data and imported to 3D graphic software allows one to render images from any location of $3 \mathrm{D}$ scene. This feature was used for rendering $360^{\circ}$ panoramic images from the perspective of the observers located on the study site in designated with the viewshed analysis area. Renders were verified against panoramic photographs taken during the field inspection. The proposed methodology was tested on two locations of Kostrzyn nad Odrą and Słubice cities where modernization of regulation structures on Oder River is planned. Calculated percentage values of river regulation structures occupying the full field of view of the observer for 25 locations in Kostrzyn nad Odrą and 19 locations in Słubice shows insignificant visual impact. The maximum values of $0.94 \%$ and $0.26 \%$ for Kostrzyn nad Odrą and Słubice respectively, where obtained. Additionally the visualization method in the form of "Little Planet" projections was presented, which allows for full documentation of the visual impact of the structures on the landscape.
\end{abstract}

\section{Introduction}

Since the beginning of the 21 st century, scientific research has been conducted on the development of quantitative methods for assessing the impact of investments on landscape. Visual impact is considered to be the most subjective and the most difficult to assess, especially in quantitative terms [1]. In recent years, Geographic Information System (GIS) has become a major tool used for visual impact assessment. Viewshed analysis in GIS environment has been become widely accepted for visibility analysis [2,3]. Viewshed tools are based on an analysis of obstacles between the observer and analysed object. They rely only on Digital Surface Models (DSM) so the good quality of the model is crucial. There are many techniques of obtaining DSM models for analysis including satellite [4], photogrammetry [5] and LIDAR data $[6,7,8]$. The most commonly used nowadays are DSMs developed on the basis of LIDAR data due to high spatial resolution and accuracy. The viewshed analysis gives binary results, determining the areas from where the analysed object is visible. It does not take into account the degree to which an object is visible and ignores the distance from the observer. Although it is an extremely useful tool, it is not enough to fully analyse the visual impact. The second approach to visual impact assessment often used in studies is the analysis of photographs implemented with analysed objects which simulates the perspective from the human-eye instead of 2D maps [9,10]. This approach gives more human-friendly results but is difficult to apply on large scale. The best solution seems to be a combination of these methods in order to obtain quantified results in the form of 2D map and to be able at the same time to quantify visual impact from the perspective of any observer.

The aim of this study was to develop method for quantitative visual impact assessment of river regulation structures and perform analysis on the reach of Oder River where the modernization of structures are planned.

\section{Materials}

The visual impact assessment of river structures like non-submerged groins and longitudinal dams on the Oder River bed was carried out on the basis of an Airborne Laser Scanning (ALS) point cloud. Data in the form of binary files were obtained from the Polish Central Office of Geodesy and Cartography in accordance with standard 1.2, published in 2008 by the American Society for Photogrammetry and Remote Sensing (ASPRS). The point cloud contains altitude data in the PUGW 1992 coordinate system, in relation to the Kronsztadt 86 altitude system. The point cloud contains class data of given point and the reflection intensity in the red, green and blue colours (RGB values), obtained from aerial photographs. The point cloud was developed on the basis of measurements carried out in the years 2011 - 2013, its density was varied and ranged from 4 to 12 points $\mathrm{m}^{2}$. The average altitude error does not exceed $0.15 \mathrm{~m}$. To identify the existing river regulation

* Corresponding author: rafwro@up.poznan.pl 
structures on the Oder River, orthophotomaps and materials obtained during field trip carried out on selected reach of the Oder River near Stubice and Kostrzyn nad Odrą were used. Additionally the panoramic images were created on the basis of a series of photographs taken with Olympus OMD EM-10 camera with Samyang 7.5 mm f/3.5 UMC Fish-eye lens and Manfrotto VR $360^{\circ}$ panoramic head and converted to equirectangular projection using the PTGui v11.6 software. Panoramic $360^{\circ}$ images represents full visibility coverage from the level of the observer.

\section{Methods}

The visual impact assessment of river regulation structures on the landscape was performed according to the own methodology using the potential of GIS tools (QGIS and ArcGIS), 3D graphics (Blender), panoramic photos and LIDAR data. The procedure diagram is shown in Figure 1.

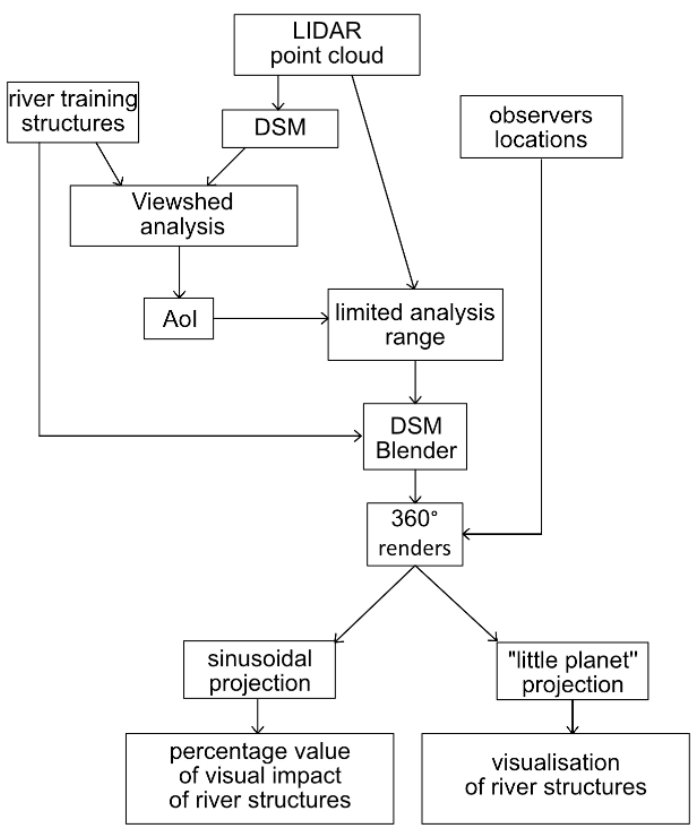

Fig. 1. Scheme for assessing the visual impact of river structures on landscape.

In the first stage, on the basis of the LIDAR point cloud, a Digital Surface Model (DSM) with a spatial resolution of $1 \mathrm{~m}$ was developed. The DSM was then supplemented with river structures (non-submerged groins and longitudinal dams) planned to be carried out as part of modernisation works on the Oder River. In the second stage, the visibility of the structures was assessed using the Viewshed tool. The analysis resulted in a raster map, where the value of 0 means that the structures are not visible and 1 means that they are visible. The viewshed analysis is based on the assessment of the occurrence of obstacles between the analysed object, and the observer. This analysis has some limitations, because it does not take into account the distance from the object and the size of the object in the field of view of the observer. The results of the Viewshed analysis allow to limit the area of further analysis. Based on the results of the Viewshed analysis and the use of the Minimum Bounding Geometry tool, the Area of Interest (AoI.shp) was determined. In the third stage, using the AoI.shp file, the point cloud was cliped to the indicated area, which was the subject of further detailed analysis.. Based on the LIDAR point cloud, in Blender v. 2.79 software, a three-dimensional terrain model was created. Blender is software for modelling and rendering images and 3D animations. It allows you to create renders from any location in 3D space. The model has been supplemented with three-dimensional models of river structures. In the fourth stage, in the Blender environment, $360^{\circ}$ panoramic renders were created for selected locations, presenting potential observer positions. The panoramic images present all surrounding objects, including: ground, vegetation and buildings, based on LIDAR data and the planned non-submerged groins and longitudinal dams. The $360^{\circ}$ panoramas obtained in Blender have been verified on the basis of $360^{\circ}$ panoramic photographs taken on study site. On the basis of $360^{\circ}$ panoramas, visualizations of so-called "little planets" were created, which show the spatial distribution of analysed objects in the field of view of the observer. In the last stage, in order to quantitatively assess the impact of river structures on the landscape, the $360^{\circ}$ panoramas were transformed using sinusoidal projection from the Equal-Area projection group using G.Projector software, developed by National Aeronautics and Space Administration (NASA) (Fig. 2).

a)

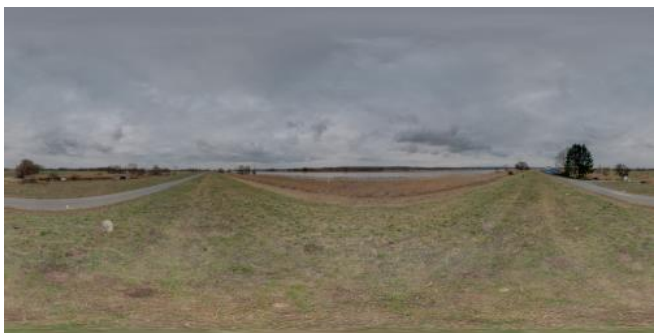

b)

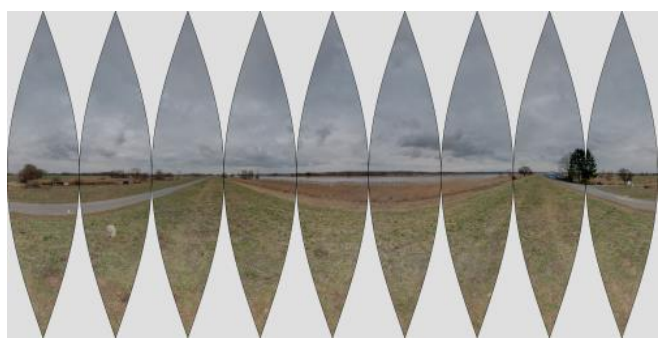

Fig. 2. Photographic panorama a) equirectangular projection, b) Equal-Area projection

\section{Results}

The visual impact assessment of river regulation structures on the Oder River was carried out on two river sections located in Słubice and Kostrzyn nad Odrą cities, where modernization of the non-submerged groins and longitudinal dams is planned (Fig. 3). 


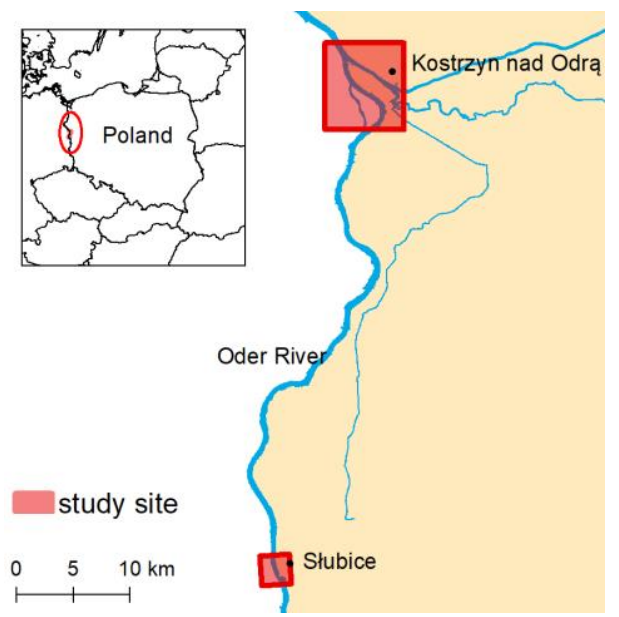

Fig. 3. Study site

In the first stage, on the basis of the LIDAR point cloud, DSM were created for selected study sites in Blender software (Fig. 4). The non-submerged groins and longitudinal dams where suplemented on the models.

a)

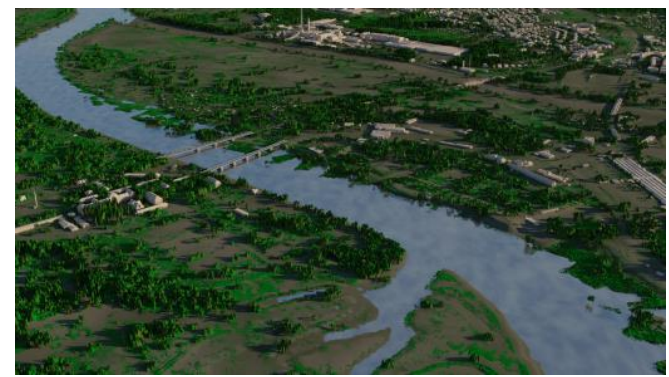

b)

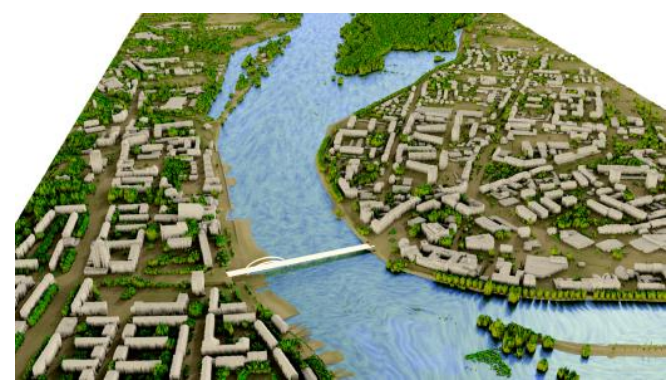

Fig. 4. DSM of a) Kostrzyn nad Odrą b) Słubice

In the next step, the Viewshed analysis was carried out. The locations from which newly built or modernized regulation structures will be visible are marked in orange (Fig. 5). The range of visibility of river training structures is usually limited to areas directly adjacent to the Odra riverbed and locally to areas located on elevated terrain. It should be noted that most often the range of visibility is limited to a floodplain or river valley.
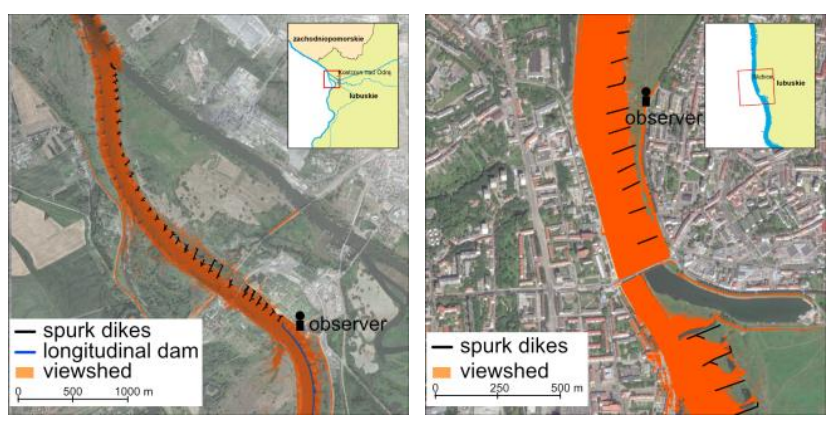

a)

b)

Fig. 5. Viewshed analysis of regulation structures of a) Kostrzyn nad Odrą b) Słubice

In order to determine the visual impact of the structures on the landscape, $360^{\circ}$ panoramas were developed in Blender at selected locations in Kostrzyn nad Odrą (Fig. 6a) and Stubice (Fig. 7a) and verified with panoramic images taken during the field inspection (Fig. $6 \mathrm{~b}$ and $7 \mathrm{~b}$ ). Then the photorealistic panoramas were supplemented with models of new and modernized regulattio structures(Fig. 6c and 7c).

a)

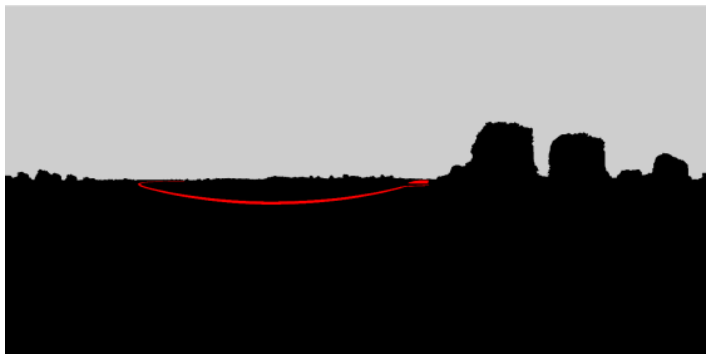

b)

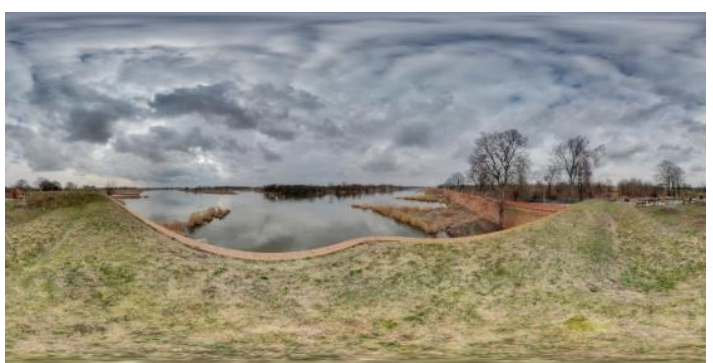

c)

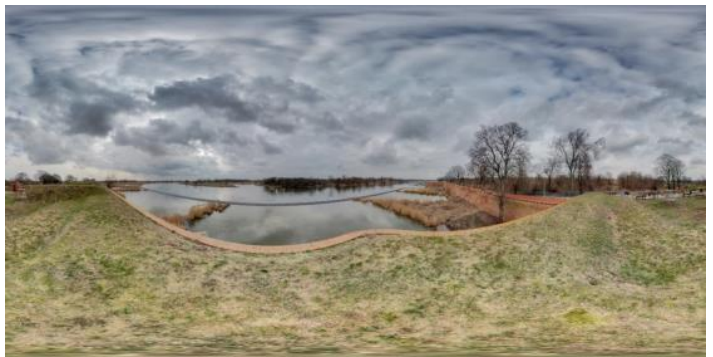

Fig. 6. $360^{\circ}$ panoramic images a) rendered in Blender, b) real photograph, c) real photograph with overlaid longitudinal dam 
a)

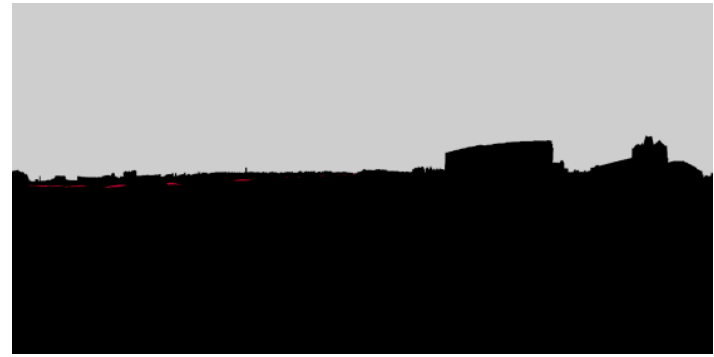

b)

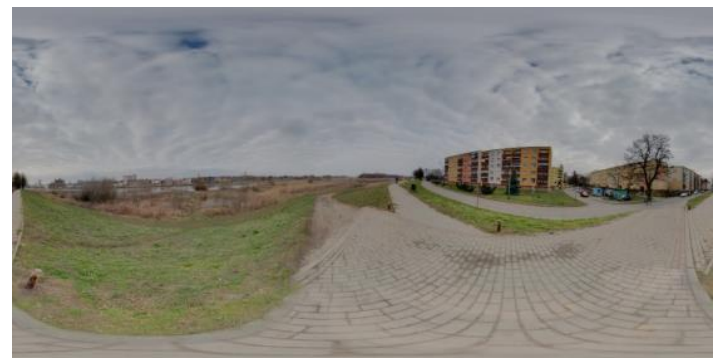

c)

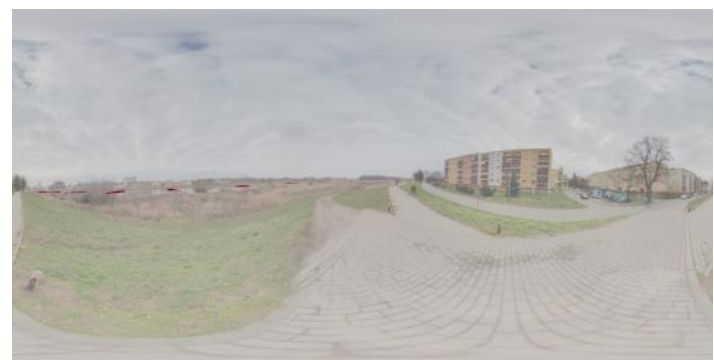

Fig. 7. $360^{\circ}$ panoramic images a) rendered in Blender, b) real photograph, c) real photograph with overlayed non-submerged groins

The presented results indicate that DSM developed for Kostrzyn nad Odrą and Słubice accurately present the current situation and allow to simulate the future impact of river regulation structures on the landscape. In the next stage, visualizations in the form of "little planets" (Fig. 8) were created on the basis of panoramas presented in Fig. 6a-c and 7a-c. The "little planet" projections show the spatial distribution of analyzed objects in the field of view of the observer, which allows for full documentation of the impact of the structure on the landscape.

As shown at the earlier stage, $360^{\circ}$ panoramas rendered in Blender can be used to assess the impact of new and modernized structures on the landscape. However, before calculations were made to determine the percentage of structures in the $360^{\circ}$ view, the panoramic images were transformed due to the occurrence of large distortions in the upper and lower part of the panorama. For this purpose, $360^{\circ}$ panoramic images were transformed using sinusoidal projection from the Equal-Area projection group using G.Projector software developed by NASA (Fig. 9). a)

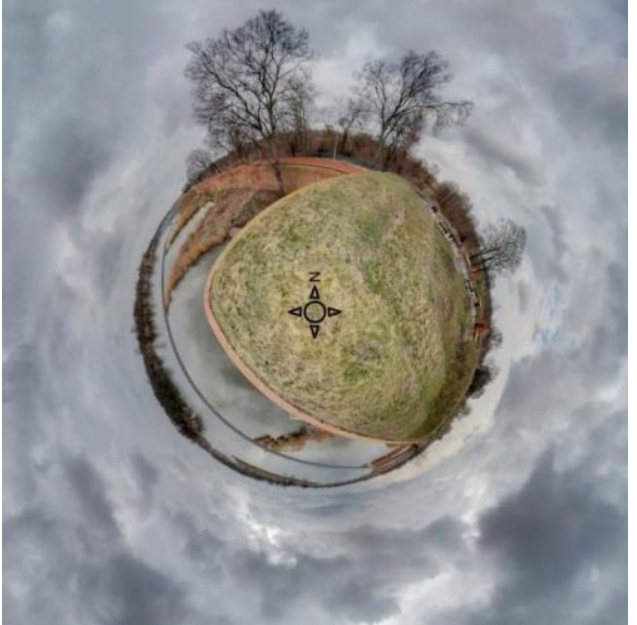

b)

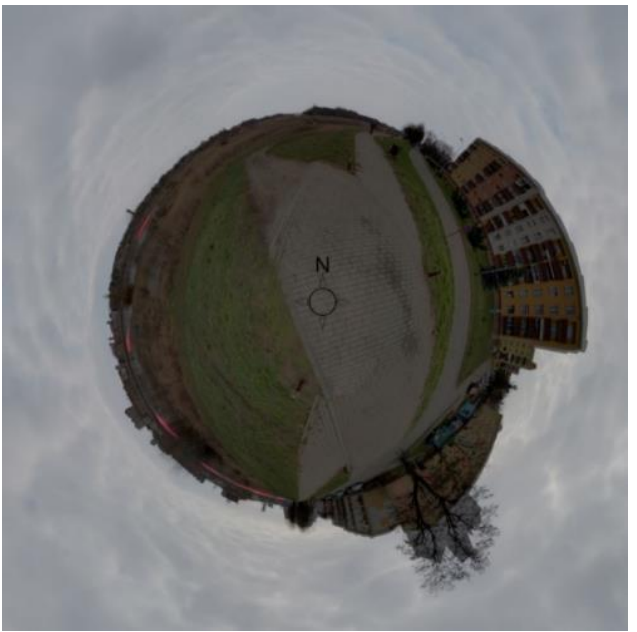

Fig. 8. "little Planet" projection a) Kostrzyn nad Odrą, b) Stubice

a)

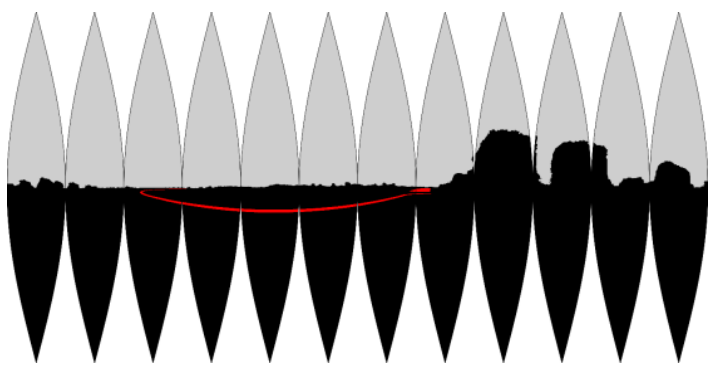

b)

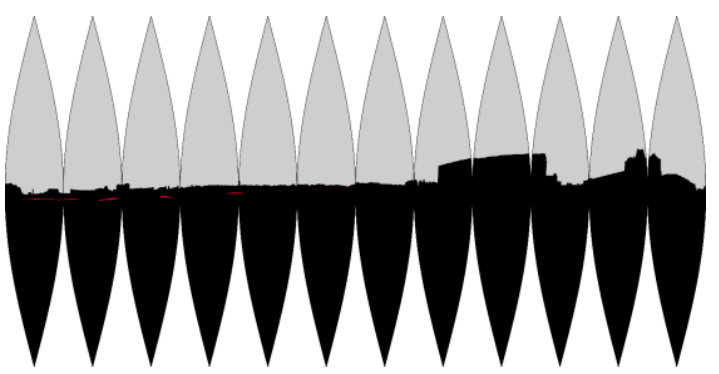

Fig. 9. Sinusoidal transformation of equirectangular images a) Kostrzyn nad Odrą, b) Słubice 
Presented methodology was used for calculating the percentage values of river regulation structures occupying the full field of view of the observer for 25 locations in Kostrzyn nad Odrą (Fig. 10a) and 19 locations in Słubice (Fig. 10b). The results obtained indicate that new and modernised regulation structures constitute maximum $0.94 \%$ and $0.26 \%$ of the $360^{\circ}$ observer field of view of Kostrzyn nad Odrą and Słubice, respectively. The values obtained do not exceed $1 \%$, which indicates a slight impact of the planned structures on the landscape.

a)

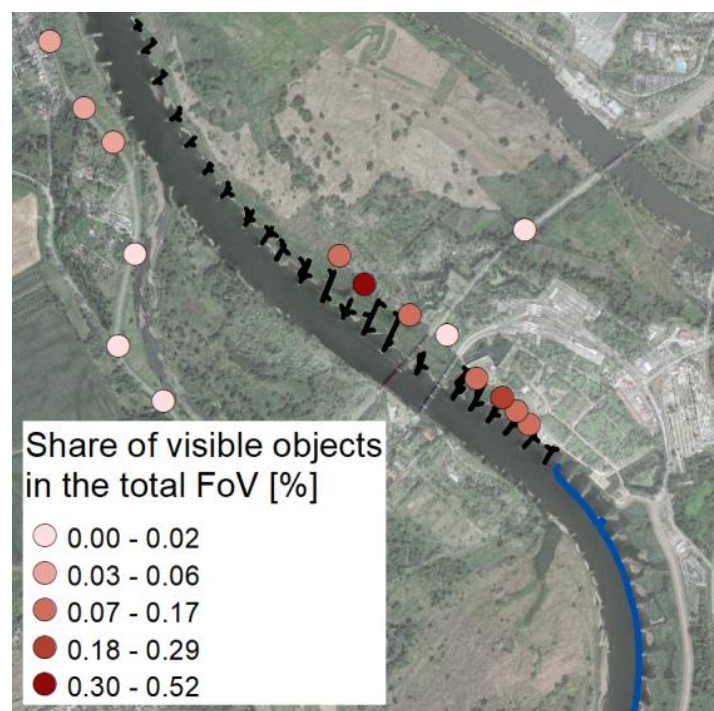

b)

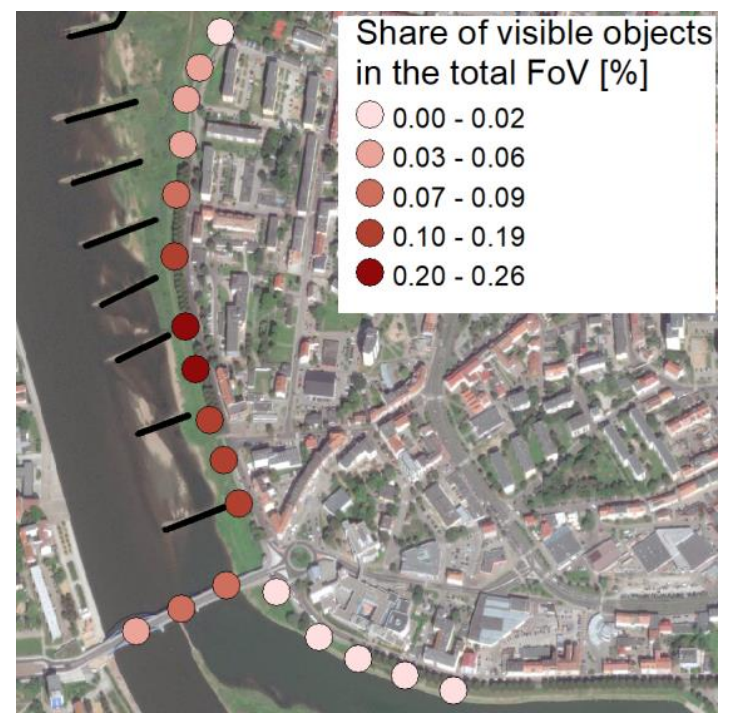

Fig. 10. Percentage share of spur dikes and longitudinal dam in filed of view of the observers of a) Kostrzyn nad Odrą b) Stubice

\section{Conclusions}

The proposed method allows for quantitative visual impact assessment in the form of 2D map and additionally allows for generating the images in $360^{\circ}$ filed of view of the observer located anywhere on the study site. Despite the visual impact is subjective matter, the calculation of percentage share of visible object in the total field of view is possible and can be used in visual impact assessment. The "Little Planet" diagrams can be generated in order to fully describe visual impact, showing the direction and cumulation of analysed regulation structures.

\section{Acknowledgements}

Publication is funded by the Polish National Agency for Academic Exchange under the International Academic Partnerships Programme from the project „Organization of the 9th International Scientific and Technical Conference entitled Environmental Engineering, Photogrammetry, Geoinformatics - Modern Technologies and Development Perspectives".

\section{References}

1. R. Wróżyński, M. Sojka, K. Pyszny. RENEW ENERG, 96 part A 625-635 (2016)

2. S. Chmielewski, P. Tompalski. APPL GEOGR, 87 1-13 (2017)

3. C. Manchado, V. Gomez-Jauregui, C. Otero. RENEW. SUSTAIN. ENERGY REV., 49, 756-767 (2015)

4. Z. Walczak, M. Sojka., R. Wróżyński, I. Laks. Water, 8(6) (2016)

5. R. Wróżyński, K. Pyszny, M. Sojka, C. Przybyła, S. Murat-Błażejewska. OPEN GEOSCI 9 281-294 (2017)

6. Z. Walczak, M. Sojka, I Laks. Rocznik Ochrona Srodowiska, 15, 2711-2724 (2013)

7. Biljecki F., Ledoux H., Stoter J. COMPUT. ENVIRON. URBAN SYST., 64, 1-18 (2017)

8. Park Y, Guldmann J. COMPUT. ENVIRON. URBAN SYST., 75, 76-89 (2019)

9. B. Takacs, M Goulden. ENVIRON. IMPACT ASSESS. REV., 76 1-9 (2019)

10. R. Wróżyński, K. Pyszny, M. Sojka. REMOTE SENS, 12, 389 (2020) 